\title{
Does a Taste of Computing Increase Computer Science Enrollment?
}

Steven McGee

The Learning Partnership

Randi McGee-Tekula

The Learning Partnership

Jennifer Duck

The Learning Partnership

Taylor White

The Learning Partnership

Eollow this and additional works at: https://ecommons.luc.edu/cs_facpubs Ronald I. Greenberg

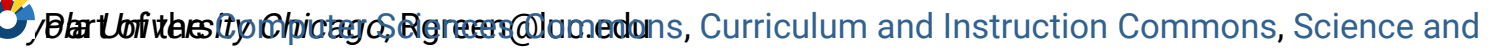
Mathematics Education Commons, and the Secondary Education Commons

Author Manuscript

See next page for additional authors

This is a pre-publication author manuscript of the final, published article.

\section{Recommended Citation}

Steven McGee, Randi McGee-Tekula, Jennifer Duck, Taylor White, Ronald I. Greenberg, Lucia Dettori, Dale F. Reed, Brenda Wilkerson, Don Yanek, Andrew Rasmussen, and Gail Chapman. Does a taste of computing increase computer science enrollment? In Proceedings of 2016 Research in Equity and Sustained Participation in Engineering, Computing, and Technology (RESPECT), August 2016.

This Article is brought to you for free and open access by the Faculty Publications and Other Works by Department at Loyola eCommons. It has been accepted for inclusion in Computer Science: Faculty Publications and Other Works by an authorized administrator of Loyola eCommons. For more information, please contact ecommons@luc.edu.

\section{(c) $($ () $\ominus$}

This work is licensed under a Creative Commons Attribution-Noncommercial-No Derivative Works 3.0 License. (C) 2009 IEEE 


\section{Authors}

Steven McGee, Randi McGee-Tekula, Jennifer Duck, Taylor White, Ronald I. Greenberg, Lucia Dettori, Dale F. Reed, Brenda Wilkerson, Don Yanek, Andrew Rasmussen, and Gail Chapman 


\section{Does a Taste of Computing Increase Computer Science Enrollment?}

\author{
Steven McGee, Randi McGee-Tekula, \\ Jennifer Duck, Taylor White \\ The Learning Partnership \\ Western Springs, United States \\ mcgee@lponline.net \\ Lucia Dettori \\ DePaul University \\ Chicago, United States
}

\author{
Brenda Wilkerson, Don Yanek, Andrew Rasmussen \\ Chicago Public Schools \\ Chicago, United States
}

\author{
Ronald I. Greenberg \\ Loyola University \\ Chicago, United States
}

\author{
Dale F. Reed \\ University of Illinois at Chicago \\ Chicago, United States
}

\author{
Gail Chapman \\ University of California at Los Angeles \\ Los Angeles, United States
}

\begin{abstract}
This study investigated the impact of the Exploring Computer Science (ECS) program on the likelihood that students of all races and gender would pursue further computer science coursework in high school. ECS is designed to foster deep engagement through equitable inquiry around computer science concepts. If the course provides a meaningful and relevant experience, it will increase students' expectancies of success as well as increase their perceived value for the field of computer science. Using survey research, we sought to measure whether the relevance of students' course experiences influenced their expectancies and value and whether those attitudes predicted whether students pursued further computer science coursework. The results indicate that students whose course experience increased expectancies for success were more likely to take another course.
\end{abstract}

Keywords-high school computer science, Exploring Computer Science, computer science attitudes

\section{INTRODUCTION}

Exploring Computer Science (ECS) is a curriculum and professional development program that was developed at the University of California at Los Angeles (UCLA) with the goal of contributing to the broadening of participation of and increasing equity for women and minorities in the field of computer science [1]. The ECS curriculum seeks to accomplish the goal of broadening participation by introducing students to the field of computer science and computational practices in a way that makes the field relevant, engaging, and stimulating for a diverse population of students. The ECS curriculum is composed of activities that are designed to engage students in computer science inquiry around meaningful problems. The ECS professional development program is designed to prepare teachers to implement the inquiry-based activities while also

This research was supported by National Science Foundation grants CNS-1138515, CNS-1138417, and CNS-1543217. Any opinions, findings, and conclusions or recommendations expressed in this material are those of the authors and do not necessarily reflect the views of the NSF. guiding teachers to build a classroom culture that is inclusive of all students. Prior studies have successfully documented the impact of the professional development on the quality of ECS implementation [e.g., 2, 3].

With continued support from the National Science Foundation, a variety of university-based and communitybased organizations are adopting the ECS program and rapidly expanding its reach to cities across the United States [4]. The NSF-funded Taste of Computing in Chicago was one of the first projects to implement and sustain the ECS curriculum and professional development program outside of Los Angeles, starting with a pilot during the 2011-12 school year [5]. In the first two full years of implementation (2012-13 and 2013-14) 26 Chicago Public Schools (CPS) enrolled over 4600 students in ECS courses. A substantial number of Taste of Computing students were female (45\%), African American (42\%), and Hispanic (42\%). Our previous research in Chicago found that students perceived the ECS course to be relevant and engaging and, as a consequence, increased their interest in taking another computer science course in high school [6]. Although increasing enrollment in further computer science is not a central goal for the ECS developers, it can be a valuable consequence of providing students with meaningful experiences in computer science.

In this research, we seek to extend our prior work to investigate the extent to which students' perceptions of the relevance of the ECS course predicts the likelihood that they will indeed take another computer science course in high school. Our research is guided by the following research question: 
Do students' perceptions of the relevance of their ECS course influence the probability that they will take additional computer science coursework in high school?

Subsequent to completing ECS, CPS students have a variety of options for taking other high school computer science courses at their schools, such as game design, web development, and database programming, in addition to AP computer science. Therefore, students who complete an ECS course have a range of options to take another computer science course. Our hypothesis is that the extent to which students perceive ECS as relevant to their lives will influence their decision-making about future coursework. The availability of a variety of computer science courses at the CPS schools in this study allows us to use students' actual decisions about taking another computer science course as the outcome measure of interest. Given the significant number of women and minority students who have participated in Taste of Computing, the conclusions from this research will be directly applicable to informing efforts to use ECS as a means to broaden participation in computer science.

\section{What ARE THE Key COMPONENTS OF THE EXPLORING COMPUTER SCIENCE CURRICULUM?}

Key to the design of the ECS curriculum is what Nasir and Hand [7] refer to as deep engagement within a community of practice. Nasir and Hand contrasted the experiences of high school boys during their participation on the basketball team versus the same boys' participation in mathematics class. The results of their analysis revealed the stark differences in access to the domain, ability to play an integral role in the community, and opportunity to express oneself, which are the foundations of deep engagement. When computer science is taught as an abstract academic subject, it privileges access to computer science to mostly Caucasian, male students [8]. In order to play an integral role in such classrooms, students must master abstract programming for programming's sake. Therefore, the opportunity to express oneself is limited to narrow abstract programming ideas. Typically, computer science courses in both high school and college have been taught in this abstract way [9]. For non-Caucasian students in low-income neighborhoods, computer instruction has tended to focus on computer applications and tends to lack opportunities for engaging in collaborative inquiry $[8,10]$.

The ECS curriculum is designed to engender deep engagement with important computer science concepts by mimicking important features of communities in which youth participate outside of the classroom. General technology use outside of school by youth of all races and genders tends to revolve around making social connections and working on practical problems [11]. Thus, access to technology outside of school is broad and students have opportunities to play an integral role within their community. In addition, students have opportunities to express themselves. Reorienting computer science instruction around problem-solving experiences that are meaningful to students has the potential to increase access to computer science content, provide students with integral roles, and create opportunities for students to express themselves $[12,13]$. At the college level, computer scientists at Carnegie Mellon made progress at increasing the representation of women in their computer science program by making such changes to the nature of instruction in their introductory courses. Faculty significantly changed the course assignments to highlight problem-solving as a primary component. Students develop technical fluency through solving problems of interest [9].

Likewise, the high school ECS curriculum focuses on making computer science concepts accessible through opportunities to use computer science concepts in meaningful ways. The curriculum supports deep engagement through three strands (equity, inquiry, and CS content) [1]. The foundational strand is equity. Inclusiveness is supported by focusing on ideas that are meaningful to students. Activities in the curriculum provide space for teachers to incorporate students' background and culture. In addition, many of the activities focus on real-life issues in the community. For example, students can make games that communicate messages about healthy eating or about the plight of undocumented students [1]. Thus, the equity component of ECS supports deep engagement by providing avenues for students to express themselves.

Resting upon equity are inquiry-based activities in which students are "expected and encouraged to help define the initial conditions of problems, utilize their prior knowledge, work collaboratively, make claims using their own words, and develop multiple representations of particular solutions." [1] In other words, given the myriad of skills that are collectively required to successfully engage in inquiry, deep engagement is brought about through the unique and integral role that each student contributes to the group inquiry. If teachers successfully bring about equitable inquiry through the first two strands, students gain access to the domain content of computer science, which is the third strand. Thus, the logic model for this research is that the extent to which students perceive the course to be relevant will serve as an indicator that deep engagement was brought about through participation in the ECS curriculum.

\section{How Do THESE ECS CURRICULUM COMPONENTS TRANSLATE InTO ClasSROOM TEACHING?}

The ECS curriculum materials and activities represent one component of the ECS program. Given the significant shift in the nature of computer science teaching required for successful implementation of ECS, teachers need significant professional development to successfully adapt to the ECS model of teaching. This need is articulated by the UCLA developers of ECS:

"Our experiences with observations in classrooms and interviews with teachers show the complexities of teaching for broadening participation in computing, and that simply adopting the curriculum without sustained professional preparation is insufficient to develop the particular pedagogical strategies and classroom norms that must accompany the ECS curriculum." [3]

In the Taste of Computing project in Chicago, about half of the participating teachers (52\%) had a background in computer science. Roughly one-third of Taste of Computing teachers had a background in business $(26 \%)$ or in a non- 
computer science area of STEM $(8 \%)$. The remaining $14 \%$ had a background in some other subject area. The teachers of traditional high school computer science courses needed to shift from foregrounding the content of computer science to now foregrounding the application of computer science concepts. The non-computer science teachers needed to develop an understanding of computer science concepts. Regardless of content background, both groups needed to shift from presenting ideas for students to master towards supporting students in developing their own understandings of the concepts. Given the prevalence of low expectations in urban settings regardless of the subject area [14], they also frequently needed to confront their own-often hiddenbiases about who can be successful in computer science.

The ECS professional development program is designed to prepare teachers to implement the inquiry-based activities while also guiding teachers to build a classroom culture that is inclusive of all students [3]. The professional development begins with a weeklong summer workshop prior to implementing ECS. There are five key components of the ECS professional development model, which was implemented in Taste of Computing. The first key component of the professional development is that teachers engage in the process of collaborative inquiry in small groups in the same way that students will engage in inquiry. This collaborative inquiry process starts with the very first activity of the workshop.

The second key component is that, throughout the week, teachers engage in inquiry specifically through a TeacherLearner-Observer model. Each small group is assigned a lesson in which the group co-plans and teaches the lesson to the rest of the participants who then engage in the lesson as learners. After the lesson, all of the participants engage in reflective discussion about the experience from the point of view of the three ECS strands (equity, inquiry, and CS content). These first two components of ECS professional development are consistent with what Desimone and Garet [15] call active learning in professional development. Their review of professional development found that active learning was an important component of professional development as it significantly influenced changes in teacher practices.

The third key component of ECS professional development is explicit discussion and reflection on equitable practices. Research-based practices for supporting inclusivity are discussed in the context of specific lessons as well as part of the lesson debriefs. These practices are essential for creating a culture of caring that helps students feel that they have the space to express themselves in class. In addition, during the workshop, the teachers read sections of Stuck in the Shallow End [8], which provides rich case study descriptions of the roots of inequity in computer science.

The fourth and fifth key components of ECS professional development are meant to sustain teachers over long time spans, which is another key dimension of effective professional development [15]. The fourth component is ongoing professional development during the school year.
Teachers are expected to attend workshops during the school year to engage in and co-plan lessons in later units of the curriculum. In addition, teachers are expected to attend a second weeklong workshop the summer after their first year of implementation.

The fifth component of ECS professional development is the development of a professional learning community. It begins in the summer workshop through the formation of small groups that engage in collaborative inquiry. It also is built up through the trust that teachers develop as they engage in tough, open discussions about equity as well as through open, honest feedback on lesson design and implementation during the workshops.

The developers of the ECS curriculum have begun to characterize the nature of classroom teaching that has emerged from the combined ECS curriculum and professional development program in Los Angeles. They have highlighted the prevalence of a variety of classroom practices that are hallmarks of the ECS approach [see 16]. It is important to keep in mind that the practices that they report are those that were both significant and could be reliably measured using an emergent coding approach. Therefore, a caveat to their research on classroom implementation is that there are likely other significant ECS practices that have not yet been reliability measured. However, there were a variety of ECSconsistent classroom practices that the researchers were able to reliably observe.

Under the equity strand, teachers were able to connect "computer science learning to equity and everyday issues" and foster the participation of all students by "encouraging collaboration." Under the CS content strand, teachers were able to model "specific computing skills or processes," explain "computer science vocabulary," and use "student-driven final projects" as a means to create what McTighe and O'Connor [17] refer to as meaningful performance goals.

However, under the inquiry strand, there was greater variability in the reliably observed classroom practices. Teachers were commonly able to "encourage exploration" and "use guided inquiry in one-on-one or in small groups." However, teachers were less likely to be observed "scaffolding learning by making explicit connections between lessons or units," "using journal writing for metacognitive reflection," and "differentiating instruction." In addition, there was significant variability in the nature of questions teachers used to facilitate student thinking. The most frequent type of question was related to checking for student understanding, which is at the lowest level of Bloom's taxonomy [18]. The least frequent type of question was related to evaluating, which is considered the highest level of Bloom's taxonomy.

This study was not able to undertake systematic classroom observations of teachings during the Taste of Computing project. However, anecdotal observations of teachers indicate that the implementation of ECS in Chicago is consistent with the kinds of observations that were made in Los Angeles. 


\section{How Do STUdENTS' EXPERIENCES IN THE COURSE INSPIRE THEM to PuRSUE Future COURSEWORK?}

In prior research on Taste of Computing, we have found a positive correlation between students' perceived relevance of their ECS courses and their attitudes towards computer science as well as their aspirations to take future similar coursework [6]. However, we have not established the convergent validity of the measure of students' aspiration to pursue future coursework. Convergent validity is the extent to which two constructs that should be related are indeed empirically related. In other words, we have not yet examined the correlation between students' aspirations and their actual choices about future coursework.

For this research, we used the Expectancy-Value-Cost model [19] as a mediator for predicting the probability that students will take another computer science course after ECS. The Expectancy-Value-Cost model is an extension of the Expectancy-Value model. The Expectancy-Value model is based on decades of research on college students' choices about majors. The basic premise of the Expectancy-Value model is that students' choice of major is dependent on how much value they put in the field as well as their expectation that they will be successful. Eccles' research has shown that people's expectation for success develops over time based on experiences with the relevant school subjects and individuals' subjective interpretation of those experiences. Eccles' research has also shown that the value that people place on a particular field develops over time and is influenced by a number of social factors, such as enjoyment, perceptions of whether the major will meet personal goals, as well as opinions of family, friends, and educators. The Expectancy-Value-Cost model incorporates the observation that perceptions of cost can thwart choices of a major if individuals feel that the major might interfere with other more valued options because of the amount of work needed to be successful in either the major or future professions linked to the major.

The Expectancy-Value model has been widely used in a variety of areas to predict future choices and behavior. For example, Eccles [20] conducted a longitudinal study of around 1,000 adolescents from southeastern Michigan. The study began when the adolescents were seniors in high school. Eccles and her colleagues surveyed the students' occupational aspirations as well as dimensions of the Expectancy-Value model as it relates to a wide variety of occupations. They analyzed the relationship between the ratings for various occupational fields and the resulting occupational choices. Over time, the adolescents' eventual job choice was strongly predicted by Expectancy-Value, not only in terms of which occupations were chosen, but also in which choices were not selected. Adolescents' eventual job choices could be traced back to those occupational fields that they rated highly on the Expectancy-Value scale.

Of the corpus of research on the link between ExpectancyValue and future aspirations, there are two in particular that are directly related to this research. The first is a study of pedagogical approaches that support growth in ExpectancyValue by Vekiri [21]. The study took place at three middle schools in Greece where students were just finishing their first year of instruction in information technology. The students were surveyed on their Expectancy-Value as it relates to information technology. They were also surveyed on the extent to which their teachers used practices that made meaningful connections to the real-world and that used active learning. These practices are similar to the equity and inquiry strands of ECS. The results indicate that exposure to meaningful experiences significantly predicted growth in the value dimension, but not the expectancy dimension. However, the extent to which students engaged in active learning did not predict changes in either the value nor expectancy dimensions. Since there was no characterization of the extent to which teachers actually engaged students in active learning, it is hard to draw firm conclusions from the report. Vekiri's study provides evidence for the hypothesis that experiences in ECS could increase the value students place on computer science by engaging them in meaningful tasks.

In the second study of interest, Dickhäuser and Stiensmeier-Pelster [22] examined computer science course selection at five middle schools in Germany. Students were free to select computer science as one of their elective choices. The Expectancy-Value model was used to predict course selection among boys and girls. Boys and girls with high Expectancy-Value were equally likely to select a computer science course. However, Expectancy-Value was significantly different for girls than boys, which explained a significant amount of the variation in course selection between boys and girls. Boys were higher in both expectancy and value. Dickhäuser and Stiensmeier-Pelster's research provides evidence for the hypothesis that Expectancy-Value is an important mediator of course selection and highlights the need to provide girls and minorities with meaningful experiences that can equitably influence Expectancy-Value.

\section{Methods}

This study took place in Chicago during the 2012-13 and 2013-14 school years, which were the first and second year of the implementation of the Taste of Computing's ECS professional development program. Teachers at all twenty-six Taste of Computing schools were invited to participate. Twelve teachers at seven Taste of Computing schools agreed to participate in the study by administering an end-of-course student survey. Table I shows the demographic breakdown of the teacher participants relative to all Taste of Computing teachers. The study sample of teachers had fewer teachers that identified as African American, more teachers that identified as Caucasian or Asian, more males, and more teachers with computer science background than in Taste of Computing as a whole. The level of teaching experience and experience in the tech industry was similar. It is important to bear in mind that at the beginning of Taste of Computing in September 2012, Chicago teachers went on a month-long strike for the first time in 25 years [23]. Anecdotally, we saw evidence of the tension surrounding the strike as several teachers expressed apprehension about outsiders collecting data since they were new to ECS or in schools that were challenging due to the overall low academic performance of the students in the school. 
TABLE I: DEMOGRAPHIC INFORMATION FOR TASTE OF COMPUTING TEACHER PARTICIPANTS RELATIVE TO TASTE OF COMPUTING TEACHERS AS A WHOLE

\begin{tabular}{|l|c|c|}
\hline Demographic Information & Sample & ToC \\
\hline$\%$ Hispanic & $8 \%$ & $8 \%$ \\
\hline$\%$ African American & $17 \%$ & $36 \%$ \\
\hline$\%$ Caucasian & $58 \%$ & $52 \%$ \\
\hline$\%$ Asian & $17 \%$ & $3 \%$ \\
\hline$\%$ Female & $42 \%$ & $52 \%$ \\
\hline Computer Science Background & $58 \%$ & $52 \%$ \\
\hline Business Background & $25 \%$ & $26 \%$ \\
\hline STEM Background & $8 \%$ & $8 \%$ \\
\hline Other Background & $8 \%$ & $14 \%$ \\
\hline Years of Teaching in General & 10 & 10 \\
\hline Years of CS Teaching & 6 & 5 \\
\hline Years of Tech Industry Experience & 7 & 9 \\
\hline
\end{tabular}

\section{A. Population}

At the time of the study, ECS was an elective course for students; therefore, students in Chicago typically opted in to take computer science. There were 952 students who completed the ECS course with the twelve participating Taste of Computing teachers. All students were invited to participate in the student surveys. We included 418 students (44\%) in the analysis who agreed to be in the study, completed the end of year survey, and whose parents consented for their participation. Table II shows the demographic information for CPS and Taste of Computing (ToC). The demographics for the full population of Taste of Computing students is similar to the demographics of CPS as a whole. Table II also shows that the demographics for the seven participating sample schools and the sample of students in ECS courses at these schools were similar. There were higher percentages of Caucasian and Asian students than in Taste of Computing as a whole. There were also fewer students on Free or Reduced lunch and students from special populations than Taste of Computing as a whole. This sample of students also had higher rates of attendance and higher prior achievement. The study sample reflects the tendency of teachers from less challenging school environments to agree to participate in the study.

\section{B. Instruments}

In the last month of the school year, the participating teachers administered an end-of-course survey, which students completed online via SurveyMonkey. The survey took approximately 15 minutes of class time to complete. If students were absent on the day that the survey was administered, teachers made an attempt to administer the survey to those students when they returned. Table III shows the survey scales that we used for this study along with the wording of the questions that comprised each scale.

We asked students the extent to which their course experience changed their interest in taking another computer science class in high school. We used a standard five-point Likert scale. The answer options ranged from decreased
TABLE II: DEMOGRAPHIC INFORMATION ABOUT TASTE OF COMPUTING STUDY PARTICIPANTS RELATIVE TO SAMPLE SCHOOLS AND CPS AS A WHOLE

\begin{tabular}{|l|c|c|c|c|}
\hline Demographic Information & Sample & $\begin{array}{c}\text { Sample } \\
\text { Schools }\end{array}$ & ToC & CPS \\
\hline$\%$ Hispanic & $48 \%$ & $44 \%$ & $42 \%$ & $43 \%$ \\
\hline$\%$ African American & $12 \%$ & $14 \%$ & $42 \%$ & $43 \%$ \\
\hline$\%$ Caucasian & $23 \%$ & $25 \%$ & $9 \%$ & $8 \%$ \\
\hline$\%$ Asian & $13 \%$ & $13 \%$ & $4 \%$ & $3 \%$ \\
\hline$\%$ Female & $47 \%$ & - & $45 \%$ & - \\
\hline$\%$ Free or Reduced Lunch & $65 \%$ & $64 \%$ & $85 \%$ & $85 \%$ \\
\hline$\%$ Special Education & $5 \%$ & $7 \%$ & $14 \%$ & $15 \%$ \\
\hline$\%$ ELL & $4 \%$ & $4 \%$ & $5 \%$ & $6 \%$ \\
\hline Attendance Rate & $95 \%$ & $93 \%$ & $89 \%$ & $87 \%$ \\
\hline EXPLORE Score & 19.5 & 19.7 & 15.8 & 16.0 \\
\hline
\end{tabular}

significantly to increased significantly. We included a middle option to indicate that their interest stayed the same.

To gauge students' perceptions of the relevance of the Exploring Computer Science course, we asked them to indicate their level of agreement with two statements about the extent to which the course helped them to meet their goals and provide skills that are relevant for other classes. Response options ranged from strongly disagree to strongly agree with a neutral option in the middle. The alpha reliability of the scale was 0.67 .

To gauge students' perceptions of their expectancy of success in the field of computer science, we asked them to indicate their level of agreement with two statements about the extent to which they extended their classroom work beyond the classroom walls. Response options ranged from strongly disagree to strongly agree with a neutral option in the middle. The alpha reliability of the scale was 0.73 .

TABLE III: END OF COURSE STUDENT SURVEY QUESTIONS

\begin{tabular}{|l|l|}
\hline $\begin{array}{l}\text { Survey } \\
\text { Scales }\end{array}$ & \multicolumn{1}{c|}{ Questions } \\
\hline $\begin{array}{l}\text { Change in } \\
\text { Interest }\end{array}$ & $\begin{array}{l}\text { How has your interest in taking another computer science } \\
\text { course changed as a result of this computer science course? }\end{array}$ \\
\hline \multirow{2}{*}{$\begin{array}{l}\text { Relevance } \\
\text { of ECS } \\
\text { Course }\end{array}$} & $\begin{array}{l}\text { This computer science class is helping me towards my } \\
\text { goals. }\end{array}$ \\
\cline { 2 - 2 } & $\begin{array}{l}\text { This computer science class gives me skills that help me in } \\
\text { other classes. }\end{array}$ \\
\hline \multirow{3}{*}{$\begin{array}{l}\text { CS } \\
\text { Expectancy }\end{array}$} & $\begin{array}{l}\text { When a question is left unanswered in this computer } \\
\text { science class, I continue to think about it afterward. }\end{array}$ \\
\cline { 2 - 3 } & $\begin{array}{l}\text { Once I start working on a computer science problem or } \\
\text { assignment, I find it hard to stop. }\end{array}$ \\
\hline \multirow{4}{*}{ CS Value } & $\begin{array}{l}\text { I will need computer science skills for my future } \\
\text { work/career. }\end{array}$ \\
\cline { 2 - 3 } & $\begin{array}{l}\text { I will use computer science in many ways throughout my } \\
\text { life. }\end{array}$ \\
\hline \multirow{2}{*}{ CS Cost } & The challenge of computer science does NOT appeal to me. \\
\cline { 2 - 2 } & Taking computer science classes is a waste of time. \\
\hline
\end{tabular}


To gauge students' perceptions of the value of the field of computer science, we asked them to indicate their level of agreement with two statements about their perceptions of computer science as a field. Response options ranged from strongly disagree to strongly agree with a neutral option in the middle. The alpha reliability of the scale was 0.84 .

To gauge students' perceptions of the costs of pursuing computer science, we asked them to indicate their level of agreement with two statements about their perceptions of barriers to computer sciences as a field. Response options ranged from strongly disagree to strongly agree with a neutral option in the middle. The alpha reliability of the scale was 0.63 .

\section{CPS District Data}

Through a data sharing agreement with CPS, we were provided with data about the students in this sample. CPS provided students' 9 th grade standardized math performance on the EXPLORE exam, the students' cumulative GPA for the year they completed ECS, their course grade, and demographic information about race, gender, and designation as special education, English Language Learner, and/or free or reduced lunch participation. CPS also provided information about any subsequent computer science courses students completed in the years after completing ECS. All seven of the participating schools provided other computer science courses for students to take after completing ECS. This last variable will be the dependent variable for the study to provide evidence on whether students' experiences in ECS predict future course taking.

\section{RESULTS}

Table IV shows a descriptive summary of the student responses to the end of course survey. Scale averages below 3 are labeled as low or decrease. Scale averages of 3 are labeled as neutral or same. Scale averages above 3 are labeled as high or increase. At the end of course, over three-fourths of the students $(71 \%)$ rated the relevance of their ECS course experience as high. More than three-fourths of the students $(83 \%)$ indicated that they highly valued the field of computer science. Over half of the students (53\%) had high expectancy of success in computer science. More than three-fourths (81\%) felt that there were low costs to participation in computer science.

When asked about how ECS changed their interest in

TABLE IV: DESCRIPTIVE STATISTICS FOR END COURSE SURVEY SCALES

\begin{tabular}{|l|c|c|c|}
\hline \multicolumn{1}{|c|}{ Variables } & Low & Neutral & High \\
\hline ECS Relevance & $10 \%$ & $19 \%$ & $71 \%$ \\
\hline CS Value & $7 \%$ & $10 \%$ & $83 \%$ \\
\hline CS Expectancy & $23 \%$ & $25 \%$ & $53 \%$ \\
\hline CS Cost & $81 \%$ & $10 \%$ & $9 \%$ \\
\hline & Decrease & Same & Increase \\
\hline $\begin{array}{l}\text { Change in Interest in } \\
\text { Future CS Course }\end{array}$ & $12 \%$ & $20 \%$ & $68 \%$ \\
\hline
\end{tabular}

taking another computer science course in high school, over two-thirds of the students increased their interest $(68 \%)$ and about one-tenth decreased their interest (12\%). Of the 418 students in the sample, 309 went on to take another computer science course in subsequent years at CPS (74\%).

As indicated above, in previous research we identified the relationship between students' perceived relevance of their course experience and the desire to take another computer science course in high school. This relationship was mediated by students expectancy and value of the field of computer science. In this research, we investigate the extent to which students' increased desire to take another computer science course increases the probability that students actually take another computer science course. We also examine whether any other factors influence the probability that students will take another computer science course.

Since the variable of whether students took another computer science course is dichotomous, we used logistic regression. The distributions of both GPA and ECS Course Grade were skewed. In addition, the distribution of EXPLORE Math scores was spread out such that there were relatively small numbers of students in any given score category. For all three of these achievement variables, we rescaled them into quartile ranges.

Table V shows the results of the logistical regressions. As a baseline model, we first examined whether any demographic or prior achievement variables predicted the probability that students would take another computer science course. We used a stepwise backward regression in which all of the variables were entered into the regression. The variable that provides the least information is removed from the equation and the regression is run again until the equation includes only variables that are statistically significant. The results of the baseline model are shown as Model 1 in Table V. The variables with a blank cell were not included in that model. The variables that were initially included in the model, but were removed through the stepwise process are indicated with NS. For variables that were statistically significant, the logit value is provided in the cell. A logit is the log of the odds that a student will take another computer science course. Positive numbers indicate that the variable increases the probability and negative numbers indicate that probability decreases.

Both prior achievement variables were statistically significant. Converting the logits into probabilities ${ }^{1}$, the model indicates that an average student in the lowest quartile of the EXPLORE has a $65 \%$ probability of taking another course, whereas an average student in the highest quartile of the EXPLORE has a $90 \%$ probability of taking another course. The results are similar for GPA. An average student in the lowest GPA quartile has a $66 \%$ probability of taking another course and an average student in the highest quartile of the GPA has a $90 \%$ probability of taking another course. There was only one statistically significant demographic variable. An

\footnotetext{
${ }^{1}$ Summing the coefficients multiplied by the value of each variable provides the predicted logit value of the model. Taking the exponential of the logit provides the odds, which is the probability of taking the course divided by the probability of not taking the course. The probability is calculated by dividing the odds by 1 plus the odds.
} 
TABLE V: RESULTS OF LOGISTIC REGRESSION PREDICTING WHETHER STUDENTS TOOK ANOTHER COMPUTER SCIENCE COURSE

\begin{tabular}{|c|c|c|}
\hline \multirow[t]{2}{*}{ Independent Variables } & \multicolumn{2}{|c|}{$\begin{array}{l}\text { Probability of Taking } \\
\text { Another Computer } \\
\text { Science Course }\end{array}$} \\
\hline & Model 1 & Model 2 \\
\hline Constant & $-1.13 * * *$ & $-0.82 *$ \\
\hline \multicolumn{3}{|l|}{ Achievement } \\
\hline EXPLORE Math & $0.53 * * *$ & $0.45 * * *$ \\
\hline GPA & $0.49 * * *$ & 0.38* \\
\hline Course Grade & & NS \\
\hline \multicolumn{3}{|l|}{ Race } \\
\hline Black & NS & \\
\hline Hispanic & NS & \\
\hline Asian & $-1.29 * * *$ & $-1.20 * * *$ \\
\hline Male & NS & \\
\hline \multicolumn{3}{|l|}{ Special Population } \\
\hline Special Education & NS & \\
\hline ELL & NS & \\
\hline Free or Reduced Lunch & NS & \\
\hline \multicolumn{3}{|l|}{ Attitudes } \\
\hline Course Relevance & & NS \\
\hline Change in Interest & & $-0.85 *$ \\
\hline \multicolumn{3}{|l|}{ Expectancy-Value-Cost Model } \\
\hline Expectancy & & $0.61 * * *$ \\
\hline Value & & NS \\
\hline Cost & & NS \\
\hline \multicolumn{3}{|l|}{ Interaction Effect } \\
\hline GPA X Change in Interest & & $0.40 *$ \\
\hline $\mathrm{R}^{2}($ Cox and Schnell) & $15 \%$ & $19 \%$ \\
\hline
\end{tabular}

average Asian student has a $54 \%$ probability of taking another course, whereas an average non-Asian student has an $81 \%$ probability of taking another course. Girls, African American, and Hispanic students were just as likely to take another computer science course as were Caucasian boys.

In Model 2, we excluded the variables that were not statistically significant in Model 1 and then added the variables from the end-of-course survey along with the ECS course grade. We tested several interaction effects, but only show the one interaction effect that was statistically significant. Again, the model was run using backwards stepwise regression. As was the case for Model 1, both prior achievement variables and whether a student identifies as Asian were statistically significant in Model 2. Students' perceptions of the relevance of their ECS course, the value of computer science as a field, and the costs of computer science do not directly predict the probability of pursuing another computer science course. Neither does students' performance in the course as measured by the course grade. These were excluded from the final model.
Students' expectancy for success in computer science was a statistically significant predictor of the probability of taking another computer science course. An average student with low expectancy has a $69 \%$ probability of taking another course, whereas an average student with high expectancy has an $88 \%$ probability of taking another course.

Students' change in interest in taking another computer science course interacts with student's prior GPA to predict the probability of taking another computer science course. Fig. 1 provides a graphical display of this interaction effect. Average students who decreased their interest in taking another computer science course hovered around the average of $75 \%$ probability of taking another course regardless of their prior GPA. Average students who increased their interest in taking another computer science had a wide range of probabilities depending on their prior GPA. Students who increased their interest but had a GPA in the lowest quartile had a $56 \%$ probability of taking another course. Students who increased their interest in taking another course and had a GPA in the highest quartile had a $93 \%$ probability of taking another course. It is unclear why students in the lowest GPA quartile who increased their interest had a lower probability of pursuing computer science than students in the lowest quartile who decreased their interest.

\section{CONCLUSIONS}

In this paper, we set out to investigate whether students' experiences in Taste of Computing influenced the probability of taking further computer science coursework in high school. Students who took ECS as part of Taste of Computing already showed an interest in computer science since it was an elective class. This predisposition towards computer science also manifests in the fact that three-fourths of the students took another computer science class. Despite the overall high probability of taking further computer science, there were

\section{Interaction of GPA and Change in Interest on the Probability of Taking a CS Course}

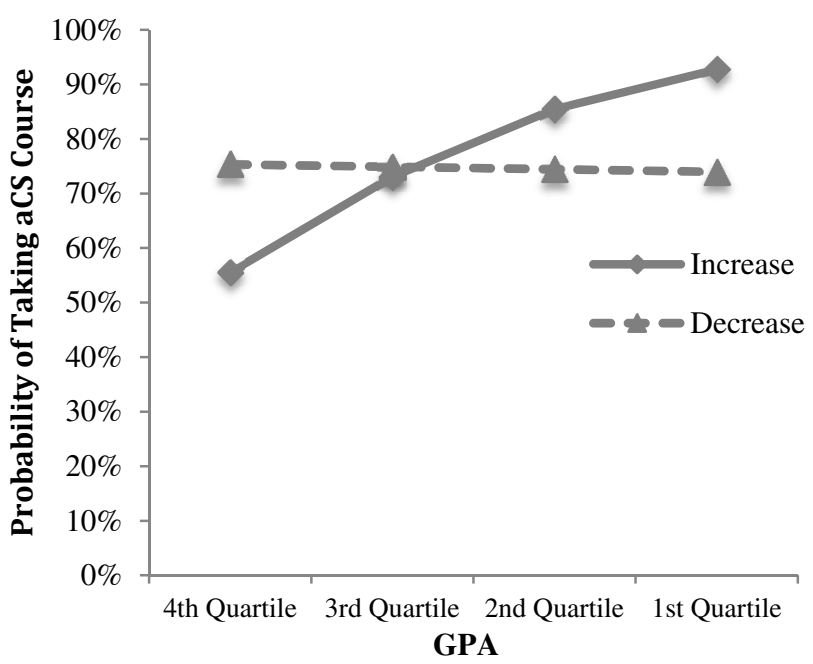

Fig. 1: Graph of the interaction effect of GPA and change in interest on the probability of taking another computer science course 
important factors that influenced that probability. There was not a direct effect of the relevance of ECS on the probability of taking another course. However, ECS course relevance has an indirect effect through its influence on students' expectancy for success, which in turn directly influences the probability of taking another computer science course, independent of students' prior achievement. These results are consistent with prior research on Expectancy-Value-Cost. Students with higher levels of expectancy increased the likelihood of taking another computer science course. However, these results do not replicate the gender differences that Dickhäuser and Stiensmeier-Pelster [22] found. Consistent with the equity strand of ECS, the effect of students' ECS course experiences on future course taking, as mediated by expectancy, was consistent for women, Hispanics and African Americans.

There are some limitations of this study. First is that the teachers who volunteered for the study represent a slightly more experienced group from higher performing schools. In future studies, we will make a concerted effort to recruit teachers from a representative sample of schools. It is possible that these results may not hold up for contexts that are more challenging. Second is the use of investigator-created measures of Expectancy-Value-Cost. More recently, Barron and Hulleman [24] have validated a shortened ExpectancyValue-Cost instrument designed to be readily administered in school settings. In future work, we will utilize their validated measure. In addition, we plan to incorporate pedagogical measures used by Vekiri [21] as a way to measure the effects of the three different strands of ECS.

Despite these limitations, this study provides preliminary evidence that expansion of the ECS program into new cities is demonstrating the potential to reach students from groups underrepresented in computer science, to meet their goals, and to increase their probability that they pursue further computer science coursework.

\section{REFERENCES}

[1] Margolis, J., Ryoo, J. J., Sandoval, C. D. M., Lee, C., Goode, J., and Chapman, G.: 'Beyond access: broadening participation in high school computer science', ACM Inroads, 2012, 3(4), pp. 72-78.

[2] Margolis, J., and Bernier, D.: 'Taking root: The LAUSD/ECS partnership story', (UCLA, 2011). Retrieved on July 5, 2016 from http://www.exploringcs.org/wp-content/uploads/2014/04/Taking-RootThe-LAUSD-ECS-Partnership-Story.pdf.

[3] Goode, J., Margolis, J., and Chapman, G.: 'Curriculum is not enough: The educational theory and research foundation of the exploring computer science professional development model', In the Proceedings of the 45th ACM Technical Symposium on Computer Science Education, 2014, pp. 493-498.

[4] https://code.org/educate/partner-districts, accessed April 10, 2015.

[5] Margolis, J., Chapman, G., Goode, J., Dettori, L., and Lewis, D.: 'A tale of three ECS partnerships and why scalability $\neq$ sustainability', (UCLA, 2013). Retrieved July 5, 2016 from http://www.exploringcs.org/wpcontent/uploads/2014/04/A-Tale-of-Three-ECS-Partnerships.pdf.

[6] Dettori, L., Greenberg, R. I., McGee, S., and Reed, D.: 'The impact of the exploring computer science instructional model in Chicago Public Schools', Computing in Science \& Engineering, 2016, 18(2), pp. 10-17.
[7] Nasir, N. S., and Hand, V.: 'From the court to the classroom: Opportunities for engagement, learning, and identity in basketball and classroom mathematics', Journal of the Learning Sciences, 2008, 17(2), pp. $143-179$.

[8] Margolis, J., Estrella, R., Goode, J., Holme, J. J., and Nao, K.: Stuck in the Shallow End: Education, Race, and Computing (MIT Press, 2010)

[9] Margolis, J., and Fisher, A.: Unlocking the Clubhouse: Women in Computing (The MIT Press, 2002).

[10] Reich, J., Murnane, R., and Willett, J.: 'The state of wiki usage in U.S. $\mathrm{K}-12$ schools : Leveraging Web 2.0 data warehouses to assess quality and equity in online learning environments', Educational Researcher, 2012, 41(7), pp. 7-15.

[11] Ito, M., Horst, H., Bittanti, M., Boyd, D., Herr-Stephenson, B., Lange, P. G., Pascoe, C. J., and Robinson, L.: 'Living and learning with new media: Summary of findings from the digital youth project. ' (The John D. and Catherine T. MacArthur Foundation Reports on Digital Media and Learning, 2008). Retireved July 5, 2016 from http://digitalyouth.ischool.berkeley.edu/files/report/digitalyouthWhitePaper.pdf .

[12] King, J., Bond, T., and Blandford, S.: 'An investigation of computer anxiety by gender and grade', Computers in Human Behavior, 2002, 18(1), pp. 69-84.

[13] Christensen, R., Knezek, G., and Overall, T.: 'Transition points for the gender gap in computer enjoyment', Journal of Research on Technology in Education, 2005, 38(1), pp. 23-37.

[14] Diamond, J. B., Randolph, A., and Spillane, J. P.: 'Teachers' expectations and sense of responsibility for student learning', Anthropology and Education Quarterly, 2004, 35(1), pp. 75-98.

[15] Desimone, L. M., and Garet, M. S.: 'Best practices in teachers' professional development in the United States', Psychology, Society, and Education, 2015, 7(3), pp. 252-263.

[16] Ryoo, J. J., Margolis, J., Goode, J., Lee, J., and Sandoval, C. D. M.: 'ECS teacher practices research findings-in brief. ' (Exploring Computer Science Project, University of California, Los Angeles Center with University of Oregon, Eugene, 2014), Retrieved July 5, 2016 from http://www.exploringcs.org/ecs-teacher-practices-research.

[17] McTighe, J., and O'Connor, K.: 'Seven practices for effective learning', Educational Leadership, 2005, 63(3), pp. 10-17.

[18] Anderson, L. W., and Krathwohl, D. R.: A taxonomy for learning, teaching, and assessing: A revision of Bloom's taxonomy of educational objectives, (Allyn \& Bacon, Pearson Education Group, 2001).

[19] Eccles, J. L.: 'Studying gender and ethnic differences in participation in path, physical science, and information technology', New Directions for Child and Adolescent Development, 2005, 110, pp. 7-14.

[20] Eccles, J. L.: 'Who am I and what am I going to do with my life? Personal and Collective Identities as Motivators of Action', Educational Pscyhologist, 2009, 44(2), pp. 78-89.

[21] Vekiri, I.: 'Information science instruction and changes in girls' and boy's expectancy and value beliefs: In search of gender-equitable pedagogical practices', Computers \& Education, 2013, 64, pp. 104-115.

[22] Dickhäuser, O., and Stiensmeier-Pelster, J.: 'Gender differences in the choice of computer courses: Applying an expectancy-value model', Social Psychology of Education, 2003, 6, pp. 173-189.

[23] McCune, G.: 'Chicago teachers union ratifies deal that ended strike', (Chicago Tribune, 2012). Retrieved July 5, 2016 from http://articles.chicagotribune.com/2012-10-04/news/sns-rt-us-usachicago-schoolsbre89309m-20121003_1_chicago-teachers-union-karenlewis-part-on-student-performance .

[24] Barron, K., and Hulleman, C.: 'Expectancy-Value-Cost model of motivation', in J. Wright, ed., International Encyclopedia of Social \& Behavioral Sciences, second edition (Elsevier, 2015), pp. 503-509. 